\title{
Errata and Addenda: A Thermal Activation Model for Noise in the DC SQUID*
}

\author{
Claudia D. Tesche $\dagger$ \\ LuTech, Inc., Berkeley, California
}

(Received November 26, 1981)

\begin{abstract}
1. The curvatures $w_{C 1}$ and $w_{C 2}$ occurring in Eq. (18) satisfy $w_{C 1}<0$, $w_{C 2}>0$.

2. The reader's attention is directed to Ref. 1, where the problem of a particle undergoing Brownian motion in a tilted sinusoidal potential in the presence of a steady state flux is treated without the necessity of introducing a dead time approximation.

The author is indebted to M. Bũettiker and R. Landauer for these suggestions.
\end{abstract}

\section{REFERENCE}

1. M. Būettiker and R. Landauer, in Nonlinear Phenomena at Phase Transitions and Instabilities, T. Riste, ed. (Plenum, New York, 1981).

*This paper appeared in J. Low Temp. Phys. 44, 199 (1981).

†Present address: IBM T. J. Watson Research Center, Yorktown Heights, N.Y. 10598. 